\title{
PATRIARCADO, SOCIEDADE E PATRIMONIALISMO
}

Neuma Aguiar

Resumo. Neste texto pesquisamos o significado do conceito de patriarcado no Pensamento Social Brasileiro. Observamos como o sistema de dominação é concebido de forma ampla e que incorpora as dimensões da sexualidade, da reprodução e da relação entre homens e mulheres no contexto de um sistema escravista. Nas sociedades onde o público se destaca do privado, sustentamos que as relações de gênero continuam patriarcais; no âmbito das sociedades patrimoniais, a intimidade entre público e privado também não resultou em uma maior participação política ou econômica das mulheres nessa esfera pela própria origem patriarcal do estamento burocrático no contexto de um patrimonialismo patriarcal.

Palavras-chave: Brasil, patriarcado, patrimonialismo, feminismo, teoria.

Patriarcado é um dos conceitos que vem despertando grande produção na literatura intelectual feminista recente e que também tem ocupado um lugar central no pensamento social brasileiro. Os debates intelectuais sobre esse tema, em cada uma dessas tradições analíticas, pouco se cruzam, dada a marginalidade conferida ao pensamento feminista nas Ciências Sociais no Brasil e a negligência do pensamento feminista local em esmiuçar os pressupostos teóricos clássicos ou aplicados à situação local para o estudo das relações entre homens e mulheres. Esse descaso impede que se examine em

Neuma Aguiar é professora da Universidade Federal de Minas Gerais. 
que medida as análises efetuadas por autores brasileiros possibilitam interpretar a condição social das mulheres, da mesma forma como eles são adequados a interpretar a situação dos homens. $\mathrm{O}$ presente texto busca comunicar essas duas vertentes de pensamento, possibilitando efetuar esse intercurso.

Raimundo Faoro, figura central nesse debate, vem argumentando que o patriarcado brasileiro cedeu lugar a um Estado Patrimonialista, observando que, ao contrário de vários países de origem anglo-saxã e sistema liberal de governo, o modelo de organização política, seguido pelo Brasil, se pauta pela dominação do público sobre o privado. Com isto Faoro se rebela contra o argumento de que uma das principais instituições sociais brasileiras, independentes do Estado, é a família, conforme as interpretações de Silvio Romero, Nísia Floresta, Oliveira Vianna, Gilberto Freyre, Joaquim Nabuco, Sérgio Buarque de Holanda e Antônio Cândido, entre outros. Esses últimos vêm analisando o patriarcado como uma herança do sistema escravista. Na literatura liberal anglo-saxã, o rompimento com a analogia entre sistema familiar e sistema de governo, em moldes patriarcais, ocorre com a proposta de uma nova interpretação do sistema político, baseada na capacidade de uso da razão dos cidadãos adultos que se organizam e negociam suas demandas públicas. Essa nova teoria política recusa os princípios absolutistas de poder das monarquias tradicionais, construindo, alternativamente, a idéia de uma sociedade civil que se governa a si própria, sem a tutela de um patriarca. Com essa recusa da analogia entre família e poder político, a esfera pública se distingue da privada. Como Faoro parte do princípio que herdamos uma tradição onde o público predomina sobre o privado, ele critica a noção de patriarcado como forma de organização privada que se apropriaria do domínio público. Uma sociedade baseada em uma instituição extremamente poderosa como a família contrariaria a visão dessa predominância do público sobre o privado, pois dessa forma o privado teria prioridade sobre o público.

$\mathrm{O}$ argumento de Faoro é extremamente persuasivo no que se refere à preponderância do Estado sobre a Economia. Porém, encontro dificuldades na subsunção da família no âmbito do Estado, um argumento que foi pouco desenvolvido pelo autor. Olhando para a produção que discute a dominação do âmbito doméstico pelo Estado, observamos que essa subserviência da família à instância pública 
é por vezes lembrada na literatura sobre totalitarismo. Quando a dominação do Estado sobre a ordem privada não é total, como no caso do Brasil, falta ampliar a linha de argumentação, apresentando de forma persuasiva a relação entre família e sistema patrimonial. Dentre os estudos de patrimonialismo que constroem essa relação, destacamos apenas o que ressalta a política de alianças da realeza por intermédio de casamentos (Adams, 1994), tema este que não foi desenvolvido pela literatura nacional.

Na literatura feminista internacional, a discussão sobre o patriarcado tem indicado a existência desse fenômeno quando existe uma ausência de regulação da esfera privada em situações onde há um notável desequilíbrio de poder dentro dessa instância. A presença de violência doméstica, por exemplo, evidencia que a separação entre público e privado se deu de forma tão ampla que ocorrem situações de dependência no interior do espaço familiar, particularmente das mulheres com relação aos homens. Nesse caso, as instituições políticas ignoram essa situação que permanece à margem do sistema normativo. O patriarcado é um sistema de poder análogo ao escravismo, observa Carole Pateman (1988). Esse diagnóstico gera uma série de demandas normativas críticas de correção das situações de arbítrio de poder dentro do espaço familiar e para além do mesmo.

No caso brasileiro, Faoro argumenta que o estamento burocrático gera uma legislação sobre a esfera privada. Porém, essa perspectiva não explica os casos de dominação arbitrária no interior da esfera familiar, como a obrigatoriedade, da parte das mulheres, de manter relações sexuais com os maridos, decorrentes de uma obrigação de atender aos desejos masculinos, independentemente das circunstâncias, e de sua própria vontade. A violência contra mulheres e a impunidade, como legítima defesa da honra masculina, consiste em outra indicação de relações patriarcais. Essas situações de arbítrio de poder na família foram amplamente documentadas pelo pensamento social brasileiro. Recupero em seguida as perspectivas sobre o patriarcado que foram desenvolvidas pelo pensamento social brasileiro, procurando observar como os teóricos identificam o fenômeno, uma vez que essa discussão contribui para a análise de relações de poder que ficaram fora do alcance do Estado.

Curiosamente, muitas teóricas feministas brasileiras e latinoamericanas rejeitam o conceito de patriarcado, o que examino mais 
adiante. Sugere-se, no final do texto, que uma dupla linha de investigação que analise simultaneamente o patrimonialismo e o patriarcado, a exemplo do que foi efetuado pela Escola Paulista de Sociologia, possa dar conta da importância que o patriarcado possui para a análise das relações familiares no Brasil. Em outras palavras, a relação entre Economia e Estado é pouco adequada para expressar a relação entre Família e Estado. A visão de Faoro, a priori, não concede espaço para a análise da sociedade, sua dinâmica, assimetrias e desigualdades.

\section{Antecedentes}

Encontro em Silvio Romero o primeiro autor a discorrer sobre o patriarcalismo no pensamento social brasileiro. Utilizando uma perspectiva da Escola de Le Play, Romero estabelece uma tipologia para classificar as famílias brasileiras em quatro categorias analíticas: patriarcal, quasi-patriarcal, tronco e instável. A primeira é composta pelo pai com sua família e as famílias de seus filhos que coabitam em uma extensão ilimitada de terras; a segunda é uma família patriarcal de menor porte, o que decorre da limitação de terras, tendo a família que se subdividir, procurando novos recursos para a sua manutenção econômica; a terceira equivaleria à classificação atual de família nuclear, pois seus membros são mais individualistas, e os filhos procuram construir o próprio espaço de habitação, destacando-se dos pais; o último tipo é uma negação da família. Romero procura, então, relacionar as características ecológico-regionais do país com os tipos de sociabilidade familiar preponderantes em cada contexto, buscando elucidar as formas de subsistência empreendidas por cada modalidade de organização social, ensejando esclarecer, no enunciado de Antônio Cândido, a adaptabilidade do povo brasileiro ao meio, situando, no processo, a questão da mestiçagem no Brasil. Não entrarei na questão racial tal como desenvolvida por Romero, tema que por si só mereceria um texto. Indico apenas que a questão é posteriormente retomada e modificada por Gilberto Freyre em sua análise do patriarcado brasileiro. O empreendimento de Romero é por ele defendido como sendo uma alternativa às visões românticas de sociedade então dominantes na literatura brasileira, pois o autor propõe que as formas de expressão literária se vinculem às variedades de experiências sociais existentes no Brasil. O método tem parentesco com o positivismo. Todavia, 
o autor preconiza um tipo de apreensão da sociedade brasileira por meio de outra corrente sociológica francesa, evitando assim qualquer aproximação de sua proposta com o enfoque de Comte ou de seus discípulos. Embora proveniente do campo literário, Romero, na observação de Antônio Cândido, procura oferecer uma base sóciocientífica à cultura brasileira. A influência de Sílvio Romero, segundo uma observação de Antônio Paim, é passível de apreensão pelas referências bibliográficas efetuadas por Oliveira Vianna, uma vez que sua proposta de trabalho foi totalmente cumprida por este último autor. Usando as mesmas perspectivas teóricas da escola de Le Play, Oliveira Vianna analisa os clãs patriarcais como sendo constituídos por uma família estendida (incluindo parentes consangüíneos, por afinidade civil, religiosa e por adoção) chefiada por um patriarca - um grande proprietário de terras - circundado por uma massa de aparentados, e/ ou de outros dependentes sem laços de parentesco. Essa população é composta por pequenos proprietários e camponeses, com seus familiares, que encontram proteção no clã, formando com ele uma comunidade de sentimentos. Essas localidades são, basicamente, ilhas autônomas de prosperidade que tudo fabricam, atraindo os despossuídos em busca de apoio político e de recursos.

Nísia Floresta aponta para a falta de acesso das mulheres à educação, a postos de trabalho e aos cargos públicos como indicações de uma injustiça dos homens, como denominou o sistema patriarcal.

Já a análise de Oliveira Vianna diz respeito ao alto sentimento de comunidade, interno ao clã patriarcal, e à ausência de laços de solidariedade entre clãs. As redes assim criadas, organizadas com base em imensa distância social entre patriarca e dependentes, são o resultado da ausência de alternativas políticas ao sistema familiar predominante na sociedade agrária. Para obter garantias o povomassa adere ao senhor, em busca de proteção social. No caso, inexistem instituições democráticas e predominam demandas de tratamento especial pelos chefes políticos que competem por favores. Oliveira Vianna critica a proposta liberal de descentralização política ao argumentar que, nas condições institucionais brasileiras, o liberalismo político representaria exatamente a preponderância do poder local, sem garantias ao povo-massa que permaneceria vulnerável ao poder dos clãs patriarcais. As mulheres seriam parte dessa massa popular que aderiria ao poder, no vazio decorrente da 
inexistência de instituições políticas. Vianna é criticado por Faoro ao conceder demasiada ênfase à autonomia e à prosperidade da ordem privada do latifúndio, em detrimento de um exame do papel do Estado Nacional no sistema de poder. Porém, é injusto com o conjunto da obra de Vianna ao negligenciar a discussão que este último entabula sobre o lugar da monarquia no jogo político dos clãs patriarcais e das propostas normativas subseqüentes que desenvolve sobre o corporativismo. Os dois autores divergem exatamente quanto ao lugar do Estado centralizador no desenvolvimento nacional.

Os princípios comunitários da ordem patriarcal, endossados por Vianna, não são enfatizados apenas pela escola de sociologia francesa. Eles são também objeto de interesse pela sociologia alemã. Tönnies os destaca quando contrasta os princípios hierárquicos, afetivos e arbitrários que regem as comunidades, com os princípios societários, impessoais e contratuais que predominam no meio urbano-industrial. Vianna, contudo, estava, mais atento em sua obra para as contribuições francesas.

Um dos autores que mais se detém na análise do patriarcado é Gilberto Freyre. Independentemente das relações entre a organização do grupo doméstico e a forma de dominação estatal, o autor mostra que o patriarcalismo estabeleceu-se no Brasil como uma estratégia da colonização portuguesa. As bases institucionais dessa dominação são o grupo doméstico rural e o regime da escravidão. A estratégia patriarcal consiste em uma política de população de um espaço territorial de grandes dimensões, com carência de povoadores e de mão-de-obra para gerar riquezas. A dominação se exerce com homens utilizando sua sexualidade como recurso para aumentar a população escrava. A relação entre homens e mulheres ocorre pelo arbítrio masculino no uso do sexo. Apesar do emprego que Gilberto Freyre faz da religião em sua análise da ordem na casa-grande e nos sobrados, o patriarcado não se efetua pela dominação religiosa, a não ser pela influência que esta exerce nas relações familiares dentro do grupo doméstico. O poder da religiosidade aparece limitado para conter a liberdade sexual masculina e o abuso sexual da mão-de-obra escrava. Para Freyre, portanto, esse abuso consiste na própria essência do patriarcado. Padres portugueses por vezes abandonam o ascetismo religioso e aderem ao patriarcado, observa Freyre (1973, p. 447), que deixa de ser, assim, em contraste com a perspectiva weberiana, uma forma de racionalidade instituída pelo 
sistema religioso, para ser uma forma de racionalidade econômica e demográfica, estratégia de povoamento e aliciamento de mão-de-obra, estabelecida no processo de colonização portuguesa. Já dois outros autores, que se inspiraram em Freyre, destacam a importância da religião na contenção dos costumes (Azevedo, 1949, p. 69-71; Duarte, 1966, p. 76-77), o que para Freyre viria apenas subseqüientemente com o processo de urbanização.

A originalidade da concepção de Freyre pode ser compreendida tomando as análises elaboradas por Weber (1964, p. 223-245) sobre patriarcalismo e religião como base de comparação. Nesse momento do texto, faço um pequeno desvio da exposição sobre o conceito de patriarcado no pensamento social brasileiro apenas para destacar a análise de Freyre das teses weberianas sobre esse tipo ideal de forma de dominação. Weber ressalta que os sistemas religiosos estabelecem uma relação íntima entre sociedade, sexualidade e erotismo, porquanto eles são também sistemas de controle da sexualidade e da reprodução. Associando sexualidade com práticas mágicas e com o comportamento religioso comunal, Weber observa, ainda, que tanto as religiões místicas, quanto as ascéticas, são hostis à sexualidade, apresentando-lhe satisfações substitutivas. A castidade é religiosamente vista como um tipo de comportamento que possibilita o desenvolvimento de qualidades carismáticas, dificultando que os sacerdotes tenham filhos e impedindo que os bens acumulados pela Igreja sejam transferidos por herança. A religião, portanto, procura eliminar o lado erótico da natureza humana, vetando socialmente tudo o que considera como sendo orgia sexual, quando enfatiza a abstinência como forma mística de alcançar a salvação, propondo, também, a evitação das emoções características do ato sexual e recomendando sua substituição pelo ascetismo vigilante, autocontrole e planejamento metódico da vida. A religião, portanto, enquanto substituta da magia, racionaliza o comportamento social pela regulação da sexualidade. Sistemas de crenças de natureza religiosa que não enfatizam a salvação por estarem mais vinculadas à vida neste mundo também se endereçam à sexualidade, podendo ser hostis às mulheres como nos casos do budismo e do confucionismo (Weber, 1964, p. 264).

A religião elimina as relações sexuais livres no interesse da regulação e legitimação do casamento (Weber, 1964, p. 237-238). Para que este controle social se efetue as mulheres são assemelhadas, pelos 
sistemas religiosos, às criaturas irracionais (ou de difícil autocontrole, isto é, com grande capacidade de ocasionar o descontrole, ou como seres capazes de causar emoção em quem as circunda, inclusive pelos desejos que podem despertar (Weber, 1964, p. 238). A contenção desses sentimentos muitas vezes se estabelece pela instituição de regras sobre as vestimentas, normatizando que sejam cobertas as partes do corpo feminino que podem suscitar desejos nos homens. Além disso, se por um lado a religião enfatiza o exercício da sexualidade dentro do casamento para o conjunto da população, ela prescreve, também, o ascetismo religioso com abstenção sexual pelos sacerdotes. O sistema religioso, portanto, é dominado por homens que estabelecem práticas de controle da sexualidade voltadas para a interdição do acesso e até mesmo da visão do corpo feminino. Portanto, os sacerdotes no Brasil, que, segundo Freyre, caem no patriarcado, distanciam-se das formas de racionalidade religiosa que controlam o comportamento sexual dos sacerdotes ou do conjunto da população. Antônio Cândido, que segue a análise de Freyre neste ponto, excetua dessas práticas libidinosas apenas os jesuítas que se esforçam por regularizar as uniões e conter a licenciosidade.

$\mathrm{Na}$ análise de Freyre sobre os sistemas de dominação, não há brechas para rebeliões, porém o exame de arquivos históricos documenta recusas da mão-de-obra escrava em dar a luz aos filhos do estupro. Estes arquivos mereceriam uma atenção cuidadosa na análise crítica do patriarcado. O caráter dessa resistência é indicado por Joaquim Nabuco (1988), cabendo aqui introduzir algumas das questões levantadas por este outro pernambucano na análise do patriarcado brasileiro.

A Igreja, por intermédio dos conventos, é a principal proprietária de escravos. Em função disso, Nabuco demonstra como nos EE.UU. a religião se torna a campeã dos direitos civis, lugar institucional em que se refugia a população negra. No caso do Brasil, esta nega os sacramentos aos escravos. $\mathrm{Na}$ ausência de racionalização das relações sociais pelo caminho religioso, os escravos se vêem lançados à promiscuidade e à magia, aponta o autor. $\mathrm{O}$ que Nabuco caracteriza como uma forma de primitivismo pode ser compreendida como uma resistência das mulheres à escravidão, rejeitando serem usadas como aparelho reprodutivo pelos senhores de terra. As mulheres (Nabuco, 1988, p.38) usam ervas daninhas e venenos, matando o feto no ventre, 
enterrando-o no mato. $\mathrm{O}$ autor interpreta o fato como uma ausência de sentimentos religiosos e atribui tal prática à falta de instrução e não como uma forma de resistência à dominação. Observa também que o feto era de propriedade do senhor, estando condenado à escravidão. O estado de gravidez, todavia, não isenta a escrava de prestar serviços forçados. A paternidade inexiste, observa Nabuco, pois a família é negada, e a escrava está sujeita à luxúria dos brancos. A amamentação realiza-se conjuntamente com os trabalhos cativos. Aos cinco anos a criança já começa a trabalhar para obter hábitos servis (Nabuco, 1988, p.50), sendo recebida como alguém que aumenta o patrimônio do senhor. A escrava jovem, diz ele, é tornada pública, isto é, um joguete de instintos (Nabuco, 1988, p.51). Castigos, açoites, marcas com ferros denotam a violência das relações sociais predominantes, além do abuso sexual contra as escravas. Com a descrição destas práticas, o autor destaca a questão moral da corrosão dos costumes pelo ataque ao direito familiar, destituindo a dignidade da mãe pela violação de sua honra e separação de seus filhos, pela negação da paternidade e pela predominância do concubinato.

Formas de exercício da dominação doméstica são transformadas durante o processo de urbanização (Freyre, 1951 e 1973; Araújo, 1994). Esta questão é trabalhada por Holanda (1971, p.113-125) quando propõe que o crescimento urbano suplanta o patriarcalismo agrário, dando margem ao aparecimento de um sistema peculiar de serviço público, efetuando uma confusão dos domínios público e privado.

Antônio Cândido, um estudioso da obra de Silvio Romero, analisa a composição e as transformações da família patriarcal no Brasil. Esta compreende, de início, um núcleo central composto por um casal com seus filhos legítimos. Na periferia, encontram-se as concubinas, filhos ilegítimos, escravos e agregados. A autoridade paterna é quase ilimitada, incluindo o direito sobre a vida dos filhos que vivem na casa dos pais, ou em casas por ele concedidas. O autor (Cândido, 1951, p.293-294) analisa a presença de filhos ilegítimos desde o início da colonização portuguesa, quando há grave desequilíbrio entre os sexos. Os portugueses mesclam-se com as filhas de chefes indígenas em uma política de alianças destinada a manter a paz social. Por outro lado, a mistura étnica e a baixa densidade da população contribuem para que a bastardia seja comum, mantendo-se ao lado do núcleo 
familiar. Mesmo depois que as proporções de homens e mulheres tornam-se mais paritárias, os concubinatos continuam a ocorrer.

Antônio Cândido retrata os papéis familiares como complementares, embora indicando a presença latente de conflitos, pois os casamentos são arranjados e a satisfação sexual é procurada fora da instituição. Filhos bastardos, dependendo do arbítrio dos pais, são legitimamente reconhecidos e dotados de herança. Isto é aceito pela esposa quando os filhos do marido nascem antes do seu casamento (situação que se contrasta com a apontada por Weber, que observou como as mulheres, para além da tese de Engels, investiram no casamento monogâmico como estratégia de defesa do patrimônio de seus filhos). Nas cidades, algumas características do sistema patriarcal são preservadas, embora, com as separações e maior liberdade sexual para as mulheres, o domínio patriarcal se atenue. Um duplo padrão de moralidade passa a existir, com permissividade para a poliginia e interdições para a poliandria.

\section{O Debate de Faoro com Antônio Cândido e Sérgio Buarque de Holanda}

Para Raimundo Faoro, a principal característica da colonização portuguesa consiste na forma de dominação estabelecida pelo governo central na condução das iniciativas empresariais, inibindo qualquer tentativa de desenvolvimento autônomo pelas unidades econômicas. Isso, aponta Faoro, representa um contraste com a organização econômica do feudalismo, cuja característica primordial é a da descentralização. $\mathrm{Na}$ Inglaterra, uma ilha mais afastada das ameaças de invasão pelos povos vizinhos, predomina um sistema econômico descentralizado. Tal não é o caso de Portugal em que o Estado absolutista é também um Estado patrimonial. As atividades empresariais, independentes do governo central, aponta o autor, são pesadamente taxadas.

Como o império português se organiza com base em instituições militares que iniciam guerras para a ampliação do domínio, o rei de Portugal procura obter fundos para remunerar seus soldados, vencer batalhas e conquistar novos territórios. O soberano, portanto, não é apenas o chefe administrativo, mas, também, o principal empreendedor econômico. Para manter a posição, o soberano necessita fundar 
cidades e oferecer incentivos aos que lá vão residir, estabelecendo tarifas protecionistas.

A economia independente que se desenvolve em plantações de finalidades comerciais, com base escravista, objeto das análises de Gilberto Freyre, é a forma que se adequa ao tipo de estratégia administrativa empregada no processo de colonização. A transferência da coroa portuguesa para o Brasil acentua a tendência centralizadora e, embora até possam ocorrer iniciativas de caráter liberal, a ordem patrimonial é predominante.

Em texto da revista da USP (Faoro, 1993) dedicado à discussão do liberalismo no Brasil, Raimundo Faoro se insurge contra um comentário de Antônio Cândido que atribui ao autor de Raízes do Brasil, em prefácio à segunda edição desse livro, o primeiro emprego dos conceitos de patrimonialismo e de burocracia, segundo uma acepção weberiana. Dessa maneira, delineia-se, com o comentário, uma possível convergência entre as análises do próprio Faoro e as de Holanda, ao apontar que ambos empregam o mesmo tipo de conceito, tendo sofrido a mesma influência teórica. Faoro, todavia, advoga para si o mais autêntico uso do conceito de patrimonialismo, apontando para duas interpretações que preponderavam na análise da formação do Estado Nacional, até o aparecimento de seu texto Os Donos do Poder, que mudaria o rumo das interpretações sociopolíticas do Brasil. Faoro aponta que a perspectiva de Holanda está bem mais próxima da de Gilberto Freyre e de Oliveira Vianna sobre o patriarcado do que da sua própria que originara a interpretação do Estado brasileiro como um Estado Patrimonial. Isto porque, justifica Faoro, as relações patrimoniais desintegram o patriarcalismo puro, pois a organização doméstica que se reproduz na ordem política o faz dentro de um quadro burocrático-administrativo. Como derivação da organização doméstica, enfatiza o autor, o patrimonialismo se aproxima do patriarcado, se destacando também, por outro lado, da burocracia impessoal, produto da transformação do feudalismo em capitalismo, uma vez que o funcionário burocrático-patrimonial considera o cargo como direito pessoal e não como posição associada a normas objetivas e impessoais. De fato, o poder patriarcal é caracterizado por Max Weber (1947, p. 346) como sendo um sistema de normas baseado na tradição. Assim, as decisões são tomadas sempre de um mesmo modo. Outro elemento básico da autoridade patriarcal é a obediência ao senhor, além da que é devotada à tradição. A modalidade, por excelência, 
da relação de dominação inquestionável é a do poder patriarcal, uma vez que não há possibilidade de que a autoridade paterna seja questionada por intermédio da justiça. Todavia, o sistema patriarcal pode constranger o senhor a tratar seus súditos de forma protetora, o que o distingue das relações que ocorrem com a exploração racional da força de trabalho sob o sistema capitalista. Faoro contrasta sua interpretação da autoridade no sistema patrimonial, ao observar que o cargo burocrático não é visto como um direito pessoal do burocrata, e sim como direito pessoal do senhor.

As relações de poder na dominação patriarcal fundamentamse na autoridade pessoal. Weber (1947, p. 396) contrasta esta forma de poder com a que ocorre nas sociedades capitalistas, quando o processo de racionalização, resultante do desenvolvimento da ciência e da tecnologia, dá origem a um sistema de normas abstratas e impessoais, sob as quais os funcionários das burocracias se organizam. Essas normas estabelecem que a pessoa no poder possui autoridade legítima para acionar regras em circunstâncias determinadas (Weber, 1978, p. 1006). Já no sistema patriarcal, a autoridade é garantida pela sujeição pessoal.

A análise de Holanda, adverte Faoro, estaria mais próxima do conceito de patriarcado do que de patrimonialismo, porque o que o primeiro produz na esfera política é a noção de que o quadro administrativo é um prolongamento da família. Nesse ponto, Faoro lembra que essa é a mesma análise elaborada por Oliveira Vianna quando este último cunhou o conceito de clã patriarcal em Populações Meridionais no Brasil, obra também amplamente usada por Gilberto Freyre em Casa-Grande e Senzala. Tudo o que se avança com esta visão da dominação patriarcal no contexto doméstico, critica Faoro, é a perspectiva política de um mandonismo, de um sultanismo, ou de uma oligarquia cujo poder não pode ser limitado. Já o liberalismo, observa o mesmo autor, se expressa constitucionalmente, enquanto no patrimonialismo estamental a oposição ao poder central só é possível porque os corpos intermediários entre governantes e governados lhe fazem resistência, ainda que por meios não constitucionais, podendo, ainda, se desenvolver um sistema de justiça, ainda que incipiente. Resta, no entanto, desenvolver a noção desse sistema normativo incipiente, uma vez que a impunidade por ocasião da violência doméstica é de fácil contastação na sociedade brasileira. 
Uma crítica parecida com essa é expressa por Florestan Fernandes quando aponta que aqueles mesmos autores não situam a dominação patriarcal em um contexto sócio-histórico mais amplo, por um processo de redução do macro ao micro, ponto ao qual retornarei mais adiante. Aponto, neste momento, apenas, que Faoro também contrapõe sua tese sobre o patrimonialismo com a da emergência da sociedade de classes pelo advento do capitalismo, adotada por alguns autores marxistas. Exemplo desta perspectiva se apresentaria pelas teses de Caio Prado Jr. que enfatizam no processo de colonização portuguesa a presença de um capitalismo mercantil, originando a burguesia na sociedade de classes. Faoro, no entanto, observa como Caio Prado Jr. aos poucos vai se rendendo à evidência de que o capitalismo brasileiro possui características peculiares, consistindo, muito mais em uma forma de capitalismo político. Neste, as empresas capitalistas são dependentes do setor público, em contraste com um capitalismo destacado do Estado, o que ocorre na situação clássica. $\mathrm{O}$ autor ressalta, com esta observação, que no patrimonialismo o poder público comanda o aparato burocrático, as forças militares e a economia.

A sociedade civil é tutelada pelo Estado. Os elementos que compreendem o setor privado (família e economia) são comandados pelo setor público, reafirma Faoro, ao contrário das teses de Freyre, Holanda ou Vianna, em que são as instituições privadas as que comandam o setor público. Embora as duas visões enunciem a perspectiva de que o público e o privado se imiscuam, as teses são discordantes quanto ao elemento dominante na relação entre os dois setores. O contraste entre estas teses é retomado recentemente por Ângela Alonso (1996). Ela observa que, para Faoro, durante o processo de colonização (ao qual acrescentamos que até mesmo antes deste processo, e, acentuadamente, depois da vinda da coroa para o Brasil), um estamento teria se apropriado do Estado, provocando o seu crescimento descomunal, o que teria vitimado o país, quando uma parte desta sociedade passa a dominá-la com o predomínio do público sobre o privado.

Ângela Alonso (1996) também destaca que o raciocínio de Sérgio Buarque de Holanda é o inverso daquele efetuado por Faoro. O patriarcalismo aparece como herança rural e o Estado patrimonial paulatinamente se edifica aprisionado nas teias familiares, isto é, o público permanece prisioneiro do âmbito privado. 
A meu ver, tanto Holanda quanto Faoro efetuam leituras adequadas de Weber, não existindo, portanto, uma versão mais correta do que a outra. Quando ambos procuram aplicar as teses weberianas ao Brasil, cada qual destaca elementos particulares de sua vasta obra. Naturalmente nenhuma teoria incorpora a totalidade do contexto social que o analista deseja explicar. Há sempre dimensões que escapam à visão teórica, particularmente quando se trata de tipos ideais. Este é o lado profícuo da aventura científica, deparar-se com o que não se encaixa nas interpretações dominantes, fazendo a Sociologia avançar. Faoro, por exemplo, ao observar que o estamento burocrático se apropria do Estado, não elabora a teia de vínculos particularistas que reúnem soberano e funcionários estamentais, uma perspectiva amplamente desenvolvida por Weber. Isto porque, sendo o patrimonialismo baseado em privilégios, as alianças familiares que se constituem por meio de casamentos e uniões, fazem parte do processo político de manutenção desses benefícios (Adams, 1994).

O patrimonialismo é uma transformação do patriarcado pelo processo de diferenciação, que se constrói a partir das relações de dependência entre o senhor e seus familiares, ou entre o soberano e os funcionários burocrático-estamentais. Isto ocorre em contraste com o feudalismo, que se organiza a partir de uma associação entre iguais. O patrimonialismo se caracteriza pela subordinação dos funcionários despossuídos ao senhor. A relação é semelhante à de escravidão, também assemelhada por Weber à devoção familiar. Foi a associação entre patrimonialismo e escravidão que levou Buarque de Holanda a aplicar o conceito com relação ao Brasil e a destacar a abolição da escravatura como um dos principais fatores explicativos do processo de mudança na sociedade brasileira. O autor também enumera que o ingresso em uma nova ordem urbana dilui a formação rural que lhe antecede. Holanda adota assim a postura de que o processo de diferenciação segundo o eixo urbano/rural explica a transformação do patriarcado. Porém, cabe apontar nesse ponto que Faoro usa as passagens patriarcado/patrimonialismo/capitalismo do Estado dentro de uma perspectiva histórico-evolucionista, esquecendo-se de que o conceito de patriarcado é empregado por Weber para analisar diferentes sociedades em distintos momentos históricos. Este é o caso, por exemplo, de sua análise sobre as relações patriarcais a leste de Elba, na Alemanha, referindo-se às condições locais 
para a mudança do sistema capitalista. A análise de Weber evoca em muitos momentos as acepções de Oliveira Vianna, Freyre e Holanda, quando o autor observa a presença de relações comunais nas ações econômicas tradicionais, orientadas pelos senhores de terra para a manutenção de sua posição social. Estas ações, portanto, não estão primordialmente voltadas para a acumulação capitalista. O interesse, contudo, paulatinamente se sobrepõe à comunidade, e o rompimento da estabilidade nas relações sociais acaba provocando a miséria e a migração. Isto é possível enunciar no contexto de sua obra, porque o conceito de patriarcado não se encontra no mesmo nível que os demais, como os de feudalismo ou patrimonialismo. Por outro lado, a constituição do Estado ou do sistema capitalista não representa a derrocada da família. As teses weberianas não advogam esta situação e sim o estabelecimento paulatino de normas, regulamentos e relações que se apresentam no espaço societário de forma distinta das que predominam no contexto familiar.

Como na visão weberiana o sistema jurídico vai se destacando e diferenciando do arbítrio do pai-de-família, resta uma questão não discutida por Faoro. Com a nova ordem patrimonial, como o conjunto de normas jurídicas repercute no interior do espaço doméstico, quem julga os conflitos: o pai ou o juiz patrimonialmente designado? Como se dá a interação entre esses corpos intermediários de poder e a família? Que tipos de casos jurídicos emergem? Como são avaliados e implementados? Pela análise de Faoro, uma vez que o patrimonialismo se estabelece parece que não apenas a sociedade civil se lhe atrela, mas a sociedade dele, também, fica cativa. Pela equação sociedade civil/sociedade, esta última deixa de ser objeto de interesse analítico e as formas de organização da vida social desaparecem, obscurecidas pelo único interesse analítico no âmbito do Estado. O problema teórico refere-se a como essa dependência do contexto doméstico do Estado afeta o grau de arbítrio do chefe-do-domicílio, até então preponderante na família. Como as regras codificadas a partir da tradição se impõem na vida cotidiana, regulando, por exemplo, a violência doméstica. Sabese que no patriarcado, o pai-de-família detém prerrogativas de vida e morte sobre os familiares. Como fica esse poder ante o patrimonialismo? Como o poder público patrimonial, enunciando uma questão exemplar, se debruça sobre a escravidão? 
Um segundo ponto refere-se ao fato de que a relação entre família e Estado faz parte da teoria sobre a democracia liberal. No caso brasileiro, a teoria do patriarcado tem servido para a análise das relações de dominação que antecederam a emergência do sistema capitalista. Como relação de poder, teóricos do liberalismo desenvolvem esta perspectiva para discutir formas alternativas de resolução de conflitos e de desenvolvimento do processo decisório na relação entre Estado e Sociedade Civil. A família patriarcal e o modelo de relações políticas derivado da família estão no cerne dessa questão. Ao poder absoluto do rei, argumentam os adversários do patriarcado que todo sujeito adulto não mais necessita ser governado por uma autoridade que se assemelha à do pai de família. Se mesmo nas sociedades que separam o contexto privado do sistema de governo, e o primeiro se sobrepõe ao último, discute-se a noção das relações arbitrárias, como se dá, no contexto privado, a relação entre família e burocracia estatal quando o governo prepondera sobre o privado e o sistema jurídico não está constitucionalmente instituído?

Para Faoro parece que o contraste entre a família como instituição privada e o poder estatal exercido pelo soberano apenas se coloca a partir da transformação do feudalismo em capitalismo. Porém, se o patriarcado é o princípio sob o qual o patrimonialismo se forma, é necessário incluir na análise a relação do patrimonialismo com a família, a não ser que a centralização governamental seja de tal forma idealizada que nada existe fora do domínio público. Nesse caso, as instituições externas ao governo centralizador deixam de ser objeto de interesse analítico e desaparecem.

\section{Uma Outra Leitura sobre Patriarcado e Estado Patrimonial: Florestan Fernandes e a Escola Paulista}

Florestan Fernandes adota um modelo interpretativo assentado em duas tradições analíticas quando estuda os processos de transformação da sociedade patriarcal no Brasil, elaborando uma fusão dos enfoques marxista e weberiano, o que lhe valeria a caracterização por Barbara Freitag de adepto da teoria crítica, a exemplo dos protagonistas da escola de Frankfurt. Assim, Fernandes discute a colonização portuguesa no contexto do desenvolvimento de um complexo Estado 
Patrimonial. A dominação se exerce no Brasil mediante as concessões de sesmarias, o que se traduziria nas doações efetuadas pela coroa a um estamento administrativo. Isto representa a concentração da propriedade ou posse da terra nas mãos de alguns, e a exclusão da massa da população que não tinha acesso aos postos burocráticos.

A escravidão representa o esteio dessa sociedade, pois ela é a semente da acumulação capitalista. A sociedade senhorial não se perpetua nem sufoca as atividades privadas, pois o excedente econômico é extraído pela coroa, permanecendo, assim, com a parte do leão.

Florestan Fernandes concorda com a tese de Faoro segundo a qual Vianna, Freyre e Holanda vêem o setor doméstico como dominante, porém, em lugar de atribuir-lhes uma concepção de feudalismo, mais claramente enunciada por Vianna, aponta que as análises elaboradas por aqueles autores da organização patriarcal da sociedade carecem de um contexto sócio-histórico. Florestan Fernandes, Fernando Henrique Cardoso, Otávio Ianni e Heleieth Saffiotti, traçam, então, um eixo de interpretação da sociedade brasileira com grande impacto, tomando a sociedade escravista do tempo do Império, como ponto de partida histórico, classificando-a simultaneamente como escravocrata e senhorial. Eles não cometem o mesmo equívoco de Faoro que consiste em considerar a sociedade civil como estando a reboque do Estado, embora advirtam que isto até ocorre para uma das parcelas da burguesia nascente que se diferencia da camada senhorial. Por outro lado, eles observam que o Estamento burocrático no estado Patrimonial possui uma relação distinta da escravidão clássica para com a coroa. Algumas das funções estamentais são efetuadas pela escravidão que se superpõe, na visão de Fernandes, à sociedade senhorial. A escravidão é distinta da que serviu de base para que Weber analisasse as suas bases jurídicas. Os escravos não são um botim de guerra, mas constituem uma mercadoria. Portanto, ao Estado Patrimonial se sobrepõe a sociedade de classes.

Florestan utiliza, então, três conceitos de estratificação: classe, estamento e casta, pois os negros na sociedade brasileira, para o autor, constituem uma casta. Os escravos, segundo Fernandes, não são uma classe, mas os agentes sociais responsáveis pela produção e acumulação primitivas, sob o capitalismo mercantil. Por outro lado, eles assumem funções que deveriam ser exercidas pela esfera 
estamental, sob o Estado Patrimonial. Os escravos, todavia, são alienados do sistema de benefícios patrimoniais, como seriam subseqüentemente marginalizados pela ordem competitiva da sociedade de classes. Florestan utiliza aqui o conceito weberiano de casta, transplantando-o culturalmente, para indicar a condição dos negros, diferenciando-a do estamento ou da classe. Saffioti adota esse mesmo conceito, não sem uma certa desconfiança, pois a autora aponta que o processo de miscigenação racial indica a existência de um intercurso social entre brancos e negros, o que seria interditado numa sociedade de castas. A miscigenação consiste em uma possibilidade de ascensão social, afirma Saffioti seguindo os passos de Antônio Cândido, na medida em que o arbítrio da camada senhorial o viabilize, indiferenciando filhos e filhas legítimos dos ilegítimos. Essa capacidade de arbítrio nas relações de poder é objeto do interesse de Fernando Henrique Cardoso que retrata a violência no sistema de mando do Rio Grande do Sul (Cardoso, 1962, p.83-84; 102-119). O arbítrio ocorre pelo processo de regressão do patrimonialismo estatal ao patrimonialismo patriarcal. Cardoso observa que os cargos são distribuídos como prebendas típicas, porém como os direitos e deveres dos cargos numa sociedade em formação ainda não tinham sido estabelecidos, preponderam os costumes patriarcais sem os limites estipulados pela tradição. Isto porque, questiona Cardoso, como é possível falar-se em tradição em um país novo como o Brasil? Portanto, em lugar de regras codificadas na punição de crimes, no âmbito jurídico, predomina a impunidade. Heleith Saffioti endossa a visão de Cardoso ao observar que a vastidão da colônia e as dificuldades de comunicação dificultam a fiscalização dos funcionários patrimoniais que esbarram na existência de uma dominação patriarcal de origem local. A partir do século XIX, indica Saffioti, estaria consolidado o poder dos chefes de parentela, levando o Estado patrimonial a se assentar muito mais num tipo de patrimonialismo patriarcal do que em um patrimonialismo estamental. Essa forma de organização de poder, em visão totalmente oposta à de Faoro, se apresenta com alto grau de compatibilidade com o desenvolvimento do capitalismo, uma vez que a exploração lucrativa da propriedade territorial levaria a um processo de acumulação que se tornaria incompatível com a estrutura da sociedade colonial de caráter estamental. Florestan todavia aponta que as várias burguesias que se formam em torno da plantação e das cidades já nascem débeis. Em 
lugar de forjarem instituições próprias, elas procuram exercer pressão e influência sobre o Estado, formando o que o autor denomina de consolidação conservadora. Esta é o resultado da moldagem da mentalidade burguesa pelas oligarquias tradicionais. Dessa forma, as velhas estruturas se vêem restauradas.

Saffioti ao desenvolver o tema do patrimonialismo patriarcal, toma dois eixos de análise: (1) a situação das mulheres brancas e das negras, no sistema senhorial, bem como a transformação que ocorre em sua posição decorrente da abolição da escravatura; (2) o processo de diferenciação, segundo os eixos: urbano/industrial e nordeste/sul, quando aquela autora atenta para o lugar que o sistema de educação nele detém. A reclusão doméstica se abranda com o ambiente das cidades, embora as mulheres brancas fiquem à margem do movimento abolicionista. No meio rural, persistem os códigos de comportamento da sociedade patriarcal com a reclusão das mulheres no âmbito doméstico. Porém, entre a desorganização da família estendida e o predomínio da família nuclear encontra-se ampla gama de experiências. A prepotência do pai-de-família vai dando lugar à função econômica de provedor. Saffioti mais recentemente aponta para um grande conjunto de contribuições na literatura feminista internacional que retoma a relação entre capitalismo e patriarcado, quando reafirma sua visão, tal como a defendida por Florestan Fernandes, que existe uma simbiose entre patriarcado, racismo e capitalismo (Saffioti, 1992, p.194-195). A autora advoga a importância de se lidar simultaneamente com as noções de dominação e exploração, na análise da dimensão de gênero nos fenômenos sociais. As questões debatidas na análise de Saffioti, no entanto, remetem-se bem mais à exploração do que à dominação. Várias discussões sobre este ponto foram detalhadas na literatura, dizendo respeito à associação entre a situação doméstica (no casamento ou derivada de emprego neste âmbito) e a de exército industrial de reserva. Em lugar de situar as mulheres casadas como uma reserva para o sistema capitalista, caberia observar como no espaço doméstico, pela dominação patriarcal, as mulheres prestam serviços aos homens, pois o ingresso em atividades capitalistas não elimina o trabalho doméstico. Os dois âmbitos, portanto, se condicionam. Outras discussões do trabalho de Saffioti, bastante revistas na literatura, dizem respeito ao impacto das crises econômicas na condição de trabalho das mulheres e à marginalização das mulheres pela introdução de tecnologias 
avançadas no processo de desenvolvimento socioeconômico, questões às quais não retornarei, restringindo-me à discussão do patriarcado. Embora Saffioti reafirme a importância do processo de urbanização na diluição do patriarcado, sua análise apresenta uma grande novidade. A industrialização que emerge com a ordem capitalista resulta no aumento das disparidades sociais entre homens e mulheres. Maria Valéria Junho Pena aponta que Saffioti neste caso sofre a influência de Engels. Quando a propriedade privada se sobrepõe, a monogamia e o direito paterno também passam a predominar, aumentando as disparidades sociais entre homens e mulheres.

Castro e Lavinas (1992, p.236-238) colocam o conceito de patriarcado como paradigmático nos estudos sobre mulheres e trabalho, porém não indicam outras contribuições brasileiras além das efetuadas por Saffioti. Em textos mais recentes, esta última autora passa a apontar a importância da dimensão de gênero como nova proposta teórica para os estudos de mulheres e, em seu trabalho sobre violência contra as mulheres, a autora nesse particular estudo não faz referência à matriz do patriarcado, embora seja essa uma das perspectivas que constituem palco das discussões feministas sobre a questão da violência (Walby, 1990). Recentemente, todavia, Saffioti retorna ao tema. A escola de Florestan Fernandes, na qual incluímos Heleieth Saffioti, faz uso de uma combinação da teoria do patriarcado com a de classes sociais. A fusão dessas duas vertentes analíticas, no entanto, é revista pela literatura feminista internacional. Quando o patriarcado é compreendido como uma dimensão do sistema capitalista, diz-se que o enfoque é dual. Saffioti, da mesma forma que Fernandes, situa o patriarcado como um antecedente do capitalismo, procurando efetuar um enfoque histórico e assim evitar o dualismo. Fernandes, no entanto, aponta para o caráter dúbio do desenrolar histórico do processo brasileiro, quando a burguesia nacional apresenta um desenvolvimento limitado pelo capitalismo global, agindo freqüentemente como estamento e não como classe. $\mathrm{O}$ conceito de patriarcado tem sido usado na literatura feminista internacional para significar as relações de poder entre homens e mulheres. As mulheres são subordinadas aos homens no sistema patriarcal. A combinação com a teoria marxista ocorre para construir uma base material para essas relações de poder. Nesse ponto, Hartmann (1981, p.1-42) fala da parceria entre o sistema capitalista e o patriarcado, observando, no entanto, que a incorporação 
das relações de dominação patriarcais no sistema capitalista tem resultado em um casamento infeliz entre feminismo e marxismo, pois as relações econômicas sempre constituem o fator principal de explicação. O objetivo da autora, contudo, é o de explicar as diferenças salariais entre homens e mulheres, observando que os salários masculinos são maiores do que os femininos porque incorporam a subsistência familiar, isto é, a manutenção dos filhos, inclusive a das esposas. Já dos salários femininos são subtraídos esses recursos. Capitalistas-patriarcas adotam essa norma estabelecendo um sistema diferencial de remuneração do trabalho para homens e mulheres. Este sistema de dominação garante o exercício das atividades domésticas pelas mulheres. Silvia Walby (1990) também procura explicar tanto as relações domésticas no casamento quanto as de trabalho remunerado na esfera capitalista com o conceito de patriarcado. Para esta, é o sistema capitalista que produz a cisão entre a residência e as atividades remuneradas originando uma nova situação de dependência para as mulheres. Essa nova forma de arranjo social, aponta Walby (1990), propicia o surgimento de uma também nova modalidade de patriarcado.

Porém, a tese da criação do patriarcado pelo sistema capitalista é uma visão que torna obscura as análises desenvolvidas no Brasil sobre a emergência de um patriarcalismo agrário e escravista. As formas de dominação patriarcal, no entanto, se alteram no decorrer da história aponta Walby (1990). Cabe portanto analisar como o patriarcado agrário e escravista se transforma, resultando em novas formas de dominação patriarcal ante a presença de um capitalismo privado, em sua forma econômica clássica, sob a dominância estatal. Em qualquer dessas modalidades, ocorre um processo de diferenciação que hipoteticamente resulta na criação de um estamento que se interporia entre a autoridade do mandatário e a posição dos demais membros da sociedade. Observe-se, outrossim, que a proposição de que o capitalismo gera uma nova forma de patriarcado não deve ser contrastada apenas com a produção brasileira sobre o tema, analisada mais acima, e que prevê a erosão do patriarcado com o desenvolvimento urbanoindustrial, ou com a emergência de um estamento burocrático, mas também com a própria perspectiva de Max Weber, uma vez que este último observou que um dos efeitos dos processos de racionalização e burocratização, característicos do sistema capitalista, é o da corrosão do patriarcado. A análise desenvolvida pela teoria feminista, portanto, 
entra em conflito com esta visão, pois os laços de dependência na esfera doméstica se acentuam com o desenvolvimento do capitalismo e/ou do Estado e da burocracia estamental.

O duplo enfoque analítico do público e do privado, do âmbito doméstico e do trabalho remunerado, pode explicar como o desenvolvimento da racionalidade societária no contexto do Estado ou das relações de trabalho capitalistas não resulta na superação do patriarcado. Formas particularistas continuam a rebaixar os salários femininos, a incluir as mulheres em um número restrito de ocupações e a negar-lhes acesso a funções de poder, apesar de importantes mudanças culturais. Talvez por isto, algumas autoras como Elizabeth Souza-Lobo apresentem objeções ao conceito de patriarcado. Ela cita a problematização efetuada por Sheyla Rowbotham que rejeita o conceito de patriarcado como estrutura universal e historicamente invariante das relações entre homens e mulheres. Ações políticas não poderiam mudar essa estrutura. Além disso, para o pensamento social brasileiro, o patriarcado está associado a condições de vida précapitalistas. Souza-Lobo defende, então, o uso do conceito de gênero como uma categoria analítica, propondo que este deva ser empregado em lugar de patriarcado, na medida em que o novo conceito comporta a variabilidade histórica das relações entre homens e mulheres. Embora essas relações possam ser hierárquicas, em um dado momento histórico, elas também podem tornar-se igualitárias. Teresita de Barbieri também segue essa mesma pauta analítica, recusando o conceito de patriarcado em favor do conceito de gênero. A opção pelo conceito de gênero, todavia, pode levar à perda do contexto histórico, restringindo-se a uma atenção exclusiva para com a dimensão microssociológica. $\mathrm{Na}$ retomada recente do conceito de patriarcado na literatura internacional, postula-se que é perfeitamente possível empregar os dois conceitos, de gênero e de patriarcado, observando-se, quanto ao primeiro, que ele possui conotações que não estão presentes no último. Quanto ao patriarcado e o seu lugar na história, observa-se que a diferentes momentos históricos corresponderiam distintas formas de organização patriarcal, sendo este um fenômeno variável. A tarefa acadêmica reside exatamente em analisar essa variabilidade histórica (Walby, 1990).

Já Carole Pateman (1988) tem uma visão bem distinta dessa. Ela rejeita gênero em favor de patriarcado, observando que este último conceito está muito mais ancorado na tradição das ciências humanas. 
A autora busca, então, examinar em que momento de sua construção teórica, a discussão do patriarcado não se adequa à análise das condições de vida das mulheres. Revendo autores como Locke e Maine, Pateman observa que o patriarcalismo, na teoria política clássica, se opõe ao contratualismo (Maine, 1970). Qual a consequiência, pergunta a autora, de analisar as relações conjugais como um contrato sexual? Mesmo que preponderem relações contratuais, na vida social, observa a autora, há situações arbitrárias nas relações conjugais que permanecem acima das elaborações jurídicas, uma vez que estas foram separadas pelo código liberal como pertinentes ao âmbito privado. As mudanças na organização do Estado não representam uma transformação automática do sistema jurídico ou dos códigos culturais que regem as relações entre homens e mulheres. Além disso, quando se estabelece um contrato entre membros de uma sociedade que detinham anteriormente posições de desigualdade, a relação assimétrica não é atenuada pelo pacto que as partes constituem entre si. A predominância de relações contratuais, portanto, é insuficiente para fazer cessar o patriarcado. A autora confirma as previsões estabelecidas por Zillah Eisenstein (1981) que anunciara um futuro radical para as feministas liberais quando estas se deparassem com os limites do liberalismo político para modificar o sistema de dominação patriarcal. Sylvia Walby (1992) propõe, então, analisar o desenvolvimento de duas formas de patriarcado: uma privada, baseada nos grupos domésticos, no âmbito do domicílio, e uma pública, correspondente à emergência do Estado. A autora propõe que o patriarcado público se endereça a várias dimensões além das diferenças no trabalho remunerado, incluindo-se a sexualidade, a violência e o Estado.

Walby (1990, p.19) endossa uma visão de Carole Pateman (1988) sobre as análises clássicas do patriarcado, observando que essa literatura tem estado mais voltada para o estudo da relação entre homens de gerações diferentes do que da relação entre homens e mulheres. Ela estende esta observação para a teoria weberiana, o que considero inadequado. Demonstrei acima que em suas tipificações do patriarcado Weber discute explicitamente a situação das mulheres. Pela pesquisa com autores clássicos do pensamento social brasileiro empreendida acima essa crítica também não é pertinente.

Uma importante contribuição para a análise do patriarcado a partir do contexto brasileiro é oferecida por Jeni Vaitsman (1994). A autora 
examina criticamente o sistema de classificação das famílias que as diferencia entre patriarcal ou extensa e nuclear ou burguesa, apontando que a família burguesa, de fato, é uma família patriarcal. Com a separação entre casa e trabalho, inaugura-se a divisão do sexual e do trabalho, com especialização das funções de provisão da casa e de cuidados com os filhos. O processo de modernização brasileiro, portanto, inaugura uma nova modalidade de patriarcado. A concepção de uma família patriarcal burguesa, portanto, permite explicar porque o desenvolvimento capitalista e a industrialização geram iniqüidades de gênero. Transformações sociais em ampla escala, incluindo-se nestas o processo de urbanização, têm sido apontadas como responsáveis pela criação de novos conceitos de intimidade e de esfera doméstica. Todavia, a divisão sexual também é recurso de sustentação de hierarquia no contexto privado. Desde a abolição da escravatura, boa parte da população negra migrou para as cidades, numa situação caracterizada por grande desequilíbrio entre os sexos, baixa taxa de nupcialidade e alta taxa de nascimentos ilegítimos, alta proporção de solteiros e baixo número de famílias com casamento regularizado, quando a união consensual sem legitimação jurídica consiste em um padrão de comportamento comum. Ao lado de famílias nucleares regularmente constituídas, encontra-se grande proporção de domicílios com uniões consensuais, isto é, com relações conjugais não contratuais. Chegamos, portanto a uma nova concepção de patriarcado para a análise da sociedade brasileira.

Elizabeth Dória Bilac levanta a questão da família patriarcal e do concubinato remetendo a uma discussão que se iniciara com Antônio Cândido, tendo continuado com as análises de Florestan Fernandes e de Heleieth Saffioti, sobre a predominância de relações legítimas sancionadas pelo casamento para uma parcela da sociedade e de relações ilegítimas para outra camada social. A autora (Doria Bilac, 1996) examina a situação das uniões consensuais, observando a crescente procura da justiça comum, em casos de separação, principalmente quando estas ocorrem no bojo de uniões consensuais. O direito, afirma a autora, vem se tornando mais difícil de ser burlado, a tal ponto que os homens nunca foram tão responsáveis pela sua reprodução biológica. Com o avanço da Ciência e com as possibilidades de atribuição de paternidade que dantes não existiam, criam-se novas concepções sobre a relação entre público e privado, em conjunto com 
outros temas, colocando outros desafios para o sistema jurídico e deixando antever novas possibilidades de alteração e mudança dos sistemas patriarcais.

O retorno à literatura clássica possibilitou, à luz da literatura feminista, observar a construção do conceito de patriarcado pelo pensamento social brasileiro e as modificações que nele vem sendo introduzidas em suas conotações. No texto, pesquisamos o significado do conceito de patriarcado no pensamento social brasileiro, suas conotações e discussões em torno do tema. Observamos como o sistema de dominação é concebido de forma ampla e que este incorpora as dimensões da sexualidade, da reprodução e da relação entre homens e mulheres no contexto de um sistema escravista. Observamos que uma atenção orientada exclusivamente para o âmbito da economia ou do sistema político perde de vista as relações hierárquicas no contexto doméstico. Se mesmo nas sociedades onde o público se destaca do privado as relações de gênero continuam patriarcais, no âmbito das sociedades patrimoniais a intimidade entre público e privado não resultou em uma maior participação política ou econômica das mulheres nessa esfera pela própria origem patriarcal do estamento burocrático no contexto de um patrimonialismo patriarcal. As assimetrias de poder nas relações entre homens e mulheres com o desenvolvimento da Ciência e do Sistema Jurídico podem ser transformadas historicamente, mas a análise do patriarcalismo no Brasil e em outros contextos pode documentar os obstáculos e avanços no desenvolvimento da sociedade. 
Abstract. In this text we search the meaning of the patriarchate concept in the Brazilian Social Thought. We observe how the dominance system is conceived in a wide form that incorporates the dimensions of sexuality, of reproduction and of the relationship between men and women in the context of a slavery system. We sustain that, if even in the societies where the public differs from the private, the gender relations remain patriarchal, in the scope of the patrimonial societies the involvement between public and private did not result in a larger political or economic participation of the women in this sphere for the own patriarchal origin of the bureaucracy in the context of a patriarchal patrimonialism.

Resumé. L'article examine le concept de patriarcat dans la pensée social brésiliene. On observe qui le systéme de domination incorpore les dimensions de la sexualité e des relations entre les genres dans le contexte de l'ésclavage. On defand qui dans les societés patriominalistes la indifférenciation entre les ordres publique e privées ne conduit pas a une plus grande participation politique ou économique des femmes.

\section{Referências Bibiográficas}

Adams, Julia (1994). "The familial state; elite family practices and state-making in the early modern Netherlands". Theory and Society, 23/24, August.

Agarwala, Bina (org.) (1988). Structures of patriarchy: the state, the community and the household. New Delhi: Indian Association for Women's Studies.

Aguiar, Neuma (org.) (1984). A mulher na força de trabalho na América Latina. Rio de Janeiro: Vozes.

Azevedo, Fernando de (1949). Canaviais e engenhos na vida política do Brasil. São Paulo: Edições Melhoramentos.

ButLer, Melissa A (1978). "Early liberal roots of feminism: John Locke and the attack on patriarchy". American Political Science Review, n. ${ }^{\circ} 72$.

CowArd, Rosalind (1983). Patriarchal precedents: sexuality and social relations. Londres: Routledge and Kegan Paul. 
Crompton, Rosemary (1993). Class and stratification: an introduction to current debates. Cambridge: Polity Press.

Crompton, Rosemary, Mann, Michael (eds.) (1994). Gender and stratification. Cambridge: The Polity Press.

DORIA BILAC, Elizabeth (1996). "Mãe certa, pai incerto: da construção social à normatização jurídica da paternidade e da filiação". Trabalho apresentado ao XX Encontro Anual da ANPOCS, 96GTO821.DOC.

DuARTE, Nestor (1966). A ordem privada e a organização política nacional. São Paulo: Companhia Editora Nacional.

EISENSTEIN, Zillah (1979). Capitalist patriarchy and the case for socialist feminism. New York: Monthly Review Press.

New York: Longman.

(1981). The radical future of liberal feminism.

FAORO, Raimundo (1958). Os donos do poder. Porto Alegre: Globo.

(1993). "A aventura liberal numa ordem patrimonialista. Dossiê liberalismo, neoliberalismo". Revista da USP, n. ${ }^{\circ}$ 17, março-maio.

Hartmann, Heidi (1981). "The unhappy marriage of marxism and feminism: towards a more progressive union". Women and Revolution: A Discussion of the Unhappy Marriage of Marxism and Feminism, Lydia Sargent (ed.) p. 1-41.

Land, H. (1980). “The Family Wage”. Feminist Review, n. ${ }^{\circ}$ 6, p. 55-77.

Locke, John (1967). Two treatises of government. Organizada por P. Laslett. Cambridge: Cambridge University Press.

Maine, Henry Summer (1970). Ancient law. Gloucester, Mass.: Peter Smith.

Pateman, Carole (1988). The sexual contract. Stanford, California: Stanford University Press.

(1989). The disorder of women: democracy, feminism and political theory. Stanford, California: Stanford University Press.

Savage, Mike e Witz, Ann.(orgs). Gender and bureaucracy. Oxford: Blackwell Publishers 
Shanley, Lindon e Pateman, Carole (1989). Feminist interpretations and political theory. The Pennsylvania State University Press.

Vaitsman, Jeni (1994). Flexíveis e plurais: identidade, casamento e família em circunstâncias pós-modernas. Rio de Janeiro: Rocco.

Vianna, Oliveira (1938). Populações meridionais do Brasil. São Paulo: Companhia Editora Nacional.

(1955). Instituições políticas brasileiras. Rio de Janeiro: Livraria José Olympio Editora.

WaLby, Silvia (1990). Theorizing patriarchy. Oxford: Brasil Blackwell.

Weber, Max (1947). The theory of social and economic organization. Organizada por T. Parsons. Glencoe-Ill: The Free Press e The Falcon Wing Press.

(1964). Sociology of religion. Boston: Beacon Press.

(1978). Economy and society. Organizada por Guenther Roth e Claus Wittich. Berkeley: The University of California Press, 2 vols.

(1961). General economic history. New York:

Collier Books.

Witz, Ann (1992). Professions and patriarchy. Londres e New York: Routledge. 